\title{
MASCULINIDADES, CAMBIOS SOCIALES Y REPRESENTACIÓN EN LA CULTURA DE MASAS
}

\author{
Iván Sambade Baquerín \\ Universidad de Valladolid, España \\ ivansambade@gmail.com
}

RESUMEN: En la actualidad, asistimos a una significativa transformación de los modelos de representación de las masculinidades. Metrosexuales, übersexuales y spornosexuales representan una nueva ubicación social de la masculinidad, en la que los hombres se posicionan como objetos de deseo. ¿Existe una relación sociológica entre estas representaciones y los cambios sociales impulsados por los movimientos feministas?

Las conquistas políticas del feminismo han acontecido al mismo tiempo que la transformación de los procesos de producción y mercado constitutivos del capitalismo global y la sociedad de la información. Desde esta perspectiva, es necesario realizar un análisis que pondere la medida en que las representaciones de las masculinidades responden, bien a la lógica de la Igualdad, bien a los flujos económicos globales.

Palabras clave: masculinidades, cultura de masas, sociedad capitalista de la información, feminismo, cambios sociales.

\section{MASCULINITIES, SOCIAL CHANGES AND REPRESENTATION IN MASS CULTURE}

ABSTRACT: Nowadays, there is a significant transformation of the models of representation of masculinities. Metrosexuals, ubersexuals and spornosexuals represent a new social location of masculinity in which men are positioned as objects of desire. Is there a sociological relationship between these representations and the social changes promoted by feminist movements?

The political achievements of egalitarian feminism have emerged together with a substantial transformation of the productive processes and the market within 
the global capitalism and the society of information. From this perspective, we must evaluate if the representations of masculinities adjust to the logics of Gender Equality, or if they are closer to the economic flows of market systems.

Keywords: Masculinities, mass culture, capitalist society of information, feminism, social changes.

Recibido: 30 de octubre de 2018 Aceptado: 28 de noviembre de 2018

\section{Introducción}

En los últimos treinta años, hemos asistido a cambios novedosos y significativos en la representación de los hombres. Redefinidos dentro de la cultura audiovisual propia de la sociedad de consumo-informacional, los modelos hegemónicos de masculinidad han adoptado cánones estéticos que, aparentemente, ubican a los hombres como objetos de deseo. En sucesivas décadas, hemos asistido a la emergencia de distintos modelos de masculinidad como metrosexuales, ubersexuales y spornosexuales, todos ellos caracterizados por el cuidado de la imagen personal y un estilo de vida sofisticado, en el que los hombres se muestran como sujetos que desean ser deseados. Desde una perspectiva ética de la justicia, cabe preguntarse por el sentido de este cambio en la representación de las masculinidades: ¿Existe una relación sociológica entre los nuevos modelos estéticos de masculinidad y los cambios sociales impulsados por los movimientos feministas?

La transformación de los modelos de masculinidad podría estar vinculada con los cambios sociales inducidos por el feminismo radical que, entre otras cuestiones, centró gran parte de su lucha en la liberación sexual de las mujeres. En este sentido, los modelos estéticos de representación de las masculinidades responderían al posicionamiento de las mujeres como sujetos de deseo. Por el contrario, si bien la emergencia del capitalismo global originó en sus albores una coyuntura social facilitadora de las acciones feministas de emancipación de las mujeres, su evolución hacia la sociedad informacional de consumo podría estar generado un estado de suspensión, e incluso involución, del cambio social hacia la igualdad entre los sexos. De este modo, los modelos de masculinidad constituirían una nueva mascarada del patriarcado de consentimiento, alimentando la ficción de un cambio incompleto (la igualdad social entre mujeres y hombres), e induciendo a los hombres a identificarse como sujetos de poder social, fundamentalmente respecto de las mujeres.

Las representaciones audiovisuales de los modelos de género constituyen uno de los principales mecanismos de normalización de hombres y mujeres en las sociedades de la información. El discurso fragmentado y esquemático que proyectan los mass media produce la apariencia de naturalidad en la masculini- 
dad y la femineidad normativas. Al mismo tiempo, el atractivo que la definición audiovisual les confiere seduce a hombres y mujeres para identificarse con estos modelos. Nos encontramos así con identidades representadas conforme a los cambios sociales y las dinámicas socioeconómicas del capitalismo global, es decir; con sujetos de éxito social bajo las ficciones de la igualdad y la meritocracia. Pero un análisis profundo de estas representaciones nos muestra que los sujetos del discurso audiovisual siguen siendo los hombres, mientras que las mujeres ocupan posiciones subalternas.

La normalización ejercida por las nuevas definiciones de lo masculino inicia su juego de poder y seducción en el espacio virtual para acabar incardinándose en los cuerpos y las prácticas de los hombres. Fenómenos sociales como la construcción del cuerpo masculino a través del bodybuilding y el protagonismo de las conductas suicida, antisocial y violenta (especialmente hacia las mujeres, pero también hacia otros hombres) son claras manifestaciones de la reproducción social de formas hegemónicas de masculinidad y, por consiguiente, de la estructura de discriminación de las mujeres. La alianza entre el patriarcado y el capitalismo informacional es la urdimbre en la que se gesta la nueva masculinidad hegemónica.

\section{Objetivos}

El objetivo principal de este trabajo es realizar un análisis que pueda esclarecer tanto la naturaleza patriarcal como el subsiguiente sesgo androcéntrico de los nuevos modelos de representación de las masculinidades. Si pretendemos que el estudio de las masculinidades contribuya simultáneamente a la emancipación social de las mujeres y al florecimiento humano de los hombres, entonces sólo cabe reconocer el legado de la hermenéutica feminista (la perspectiva de género) como el marco teórico-crítico fundamental desde el que desarrollar dichos estudios. Conceptos como "patriarcado de consentimiento" 1 , "ficción de la Igualdad"2, "metaestabilidad patriarcal"3 y "masculinidad hegemónica"4 son los ejes que guían el presente estudio. A su vez y en la medida en que este estudio se fundamenta desde dichos ejes, debe tener el objetivo de ampliar el marco conceptual que éstos sustentan, proporcionando asimismo un conocimiento científico certero acerca de las estrategias de reproducción de la estructura social de la discriminación masculina de las mujeres y de la responsabilidad de los hombres en las mismas. Este tipo de conocimiento nos permitirá identificar

1. Puleo, A. H., "Patriarcado", Amorós, C. (dir.), 10 palabras clave sobre Mujer. Estella 1995, pp. 21-54.

2. Valcárcel, A., Feminismo en el mundo global. Madrid 2008.

3. Amorós, C., La gran diferencia y sus pequeñas consecuencias... para las luchas de las mujeres. Madrid 2005.

4. Connell, R.W., Masculinities. Sydney 1995. 
los flancos del cambio de los hombres hacia formas más justas e igualitarias de masculinidad. Finalmente, este trabajo tiene el objetivo de reconocer las prácticas que los hombres ejercen como consecuencia de su socialización en los modelos estéticos de masculinidad, cerrando así el círculo foucaultiano que parte de las bio-políticas de verdad para llegar a descifrar las estrategias sociales de control social. El análisis de estas prácticas nos permitirá descubrir que los modelos hegemónico-patriarcales de masculinidad no sólo reproducen la discriminación social de las mujeres, sino que también generan frustración, infelicidad y otras formas sociales de subordinación entre los propios hombres como, por ejemplo, la violencia homófoba.

\section{Metodología}

El diseño metodológico de este trabajo es fundamentalmente cualitativo e interdisciplinar. En primer lugar, este análisis se nutrirá de los múltiples y diversos trabajos que han estudiado la representación audiovisual de las masculinidades desde la perspectiva de género y otras perspectivas afines como la teoría queer y los estudios LGTBIQ+. En este mismo orden de análisis, el trabajo emplea numerosas películas de cine como fuentes documentales. Todas las películas de cine analizadas se caracterizan por pertenecer a la cultura mainstream y por interpelar a los hombres, bien de modo directo, a través de su exclusivo protagonismo y de temáticas que han sido tradicionalmente asociadas con la masculinidad-violencia, guerra, heroísmo, autoconstrucción de uno mismo y éxito social, etc.-, bien de modo indirecto, por medio de la omnipresencia de modelos arquetípicos de masculinidad y de un sesgo marcadamente androcéntrico, a pesar de estar dirigidas a un público general. De este modo, la presencia de modelos hegemónicos de masculinidad y su dirección hacia un público objetivamente masculino han sido los dos criterios básicos para la elección de las películas seleccionadas, a su vez, siempre dentro de la cultura mainstream. Asimismo, este trabajo recurre también a la teoría crítica feminista y a la sociología de género para realizar un diagnóstico sobre la relación entre los modelos analizados y el estado de los cambios sociales hacia la igualdad de género.

Por otra parte, las hipótesis e interpretaciones que dirigen este trabajo no han prescindido de fuentes cualitativo-cuantitativas. Los estudios culturales de las masculinidades parecen abocados a un debate infinito contra el prejuicio esencialista o biologicista. En este sentido, son necesarias las investigaciones realizadas desde las ciencias experimentales que confirman una y otra vez que el peso relativo del ambiente sociocultural es más decisivo que los factores biológicos y filogenéticos en la constitución de la conducta masculina. Finalmente, este trabajo cuenta con estudios cualitativo-cuantitativos que interpretan estadísticamente la incidencia de los hombres en la conducta antisocial y violenta como consecuencia de su socialización de género. Estos 
análisis nos aportan una base sólida sobre la que interpretar los efectos socializadores de los nuevos modelos de masculinidad y el modo en que éstos siguen reproduciendo la estructura de género con sus múltiples intersecciones discriminatorias, siendo la discriminación social y simbólica de las mujeres la columna que vertebra el sistema.

\section{Cambios sociales y nuevos modelos de masculinidad: una genealogía}

A finales de los años sesenta, surge un movimiento social y cultural de vindicación y lucha por los derechos de las mujeres con importantes consecuencias políticas y sociales. Este movimiento fue denominado "la segunda ola del feminismo" ${ }^{\prime}$. La segunda ola del feminismo no sólo supuso la consecución de numerosas leyes a favor de la igualdad entre los sexos, especialmente en el terreno de los derechos reproductivos y sexuales, sino también la visibilización y la condena pública de los sistemas sociales de estratificación sexual: los patriarcados. En este contexto de cambio social y crítica pública de la desigualdad y de su ideología dominante, el machismo, aparece la llamada crisis de la masculinidad 6 .

La crisis de la masculinidad describe la situación de inseguridad y tedio vital que los hombres occidentales habrían comenzado a vivir como consecuencia de los cambios sociales impulsados por las políticas feministas. La incorporación de las mujeres al mercado de trabajo (con la consiguiente ruptura de su sujeción en la esfera social privada y el reconocimiento explícito de sus derechos en la esfera social pública), las políticas de discriminación positiva, las leyes de protección específica frente a la violencia machista y el cuestionamiento general de la legitimidad del poder/control social de los hombres, en tanto que sexo biológicamente superior, habrían causado una cierta desorientación en estos, quienes ya no podían identificarse como tales a través de los roles asociados al trabajo y el éxito en la esfera social pública, frente a las mujeres como personas encargadas del espacio privado ${ }^{7}$.

Paradójicamente, a finales de los años ochenta, la cultura popular comenzó a representar a los hombres como víctimas sociales, Ilegando incluso a justificar su violencia como una reacción frente al "acecho social" que estaban viviendo ${ }^{8}$. Obviamente, esta representación sólo puede ser el resultado de una cultura

5. Davis, F., Moving the Mountain: The Women's Movement in America since 1960. Champaign, IL, 1999.

6. Segal, L., "Los hombres tras el feminismo ¿Qué queda por decir?”, Carabí, A. y Armengol, J. M. (eds.). La masculinidad a debate. Barcelona 2008, pp. 155-177.

7. Marqués, J.V. y Osborne, R., Sexualidad y sexismo. Madrid 1991.

8. Segal, L., "Los hombres tras el feminismo... p. 156. 
androcéntrica, con su consiguiente condescendencia hacia la desorientación identitaria que la puesta en entredicho del machismo y de los dividendos patriarcales causaron en numerosos hombres ${ }^{9}$. Asimismo, esta respuesta cultural se vio reflejada en dos modelos de representación de masculinidades aparentemente dicotómicos: el hombre duro y el hombre blando ${ }^{10}$.

El hombre duro es la encarnación de la masculinidad hegemónica norteamericana. Ésta bien podría adecuarse a cualquier modelo patriarcal de masculinidad, no sólo porque la cultura norteamericana se haya expandido globalmente, sino porque este modelo se conforma sobre los ejes de la estructura patriarcal: el imperativo social heterosexual, la división sexual del trabajo y la protección masculina como mecanismo de legitimación del poder de los hombres ${ }^{11}$. En 1976, dos estudiantes de psicología, Deborah S. David y Robert Brannon ${ }^{12}$, enunciaron los cuatro imperativos que conforman la masculinidad hegemónica norteamericana en forma de consignas populares: 1. No Sissy stuff (No ser femenino); 2. The big wheel (Ser una persona importante); 3. The sturdy oak (Duro como un roble); 4. Give'em Hell (Al diablo con todos). El hombre duro se representa como la exaltación de estas cuatro consignas. Principalmente, el hombre duro es emocionalmente duro. No necesita a nadie y si lo necesita no lo demuestra. Es decir, no muestra aquellos sentimientos que tradicionalmente han sido considerados femeninos: el cariño, la emoción o el miedo entre otros. Estos sentimientos son síntomas de debilidad y el hombre de verdad es duro por dentro y duro por fuera: duro como un roble. De hecho, el disciplinamiento físico no es ni más ni menos que una preparación para el ejercicio de la violencia (Al diablo con todos). El hombre duro asume todos los riesgos aun a costa de su integridad física, pero, en última instancia, cuenta con la posibilidad de ejercer la violencia para salir airoso de cualquier situación. Así, tal y como explica Elisabeth Badinter, el hombre duro es un hombre que se muestra solitario e impasible; un varón que tiende a la huida y al aislamiento para no estar ligado a nada que pueda hacerle vulnerable. En definitiva, un "mutilado de afecto $^{\prime 13}$. Badinter describe la evolución hacia la impasibilidad de este modelo de masculinidad a través de tres personajes del cine americano: el pistolero, Rambo y Terminator. En el western, el pistolero rebosa de una masculinidad

9. Téngase en cuenta que, a pesar de los cambios sociales y frente a la errónea conciencia popular de igualdad, los hombres permanecen ocupando prácticamente de forma exclusiva las altas esferas del poder político y las posiciones de decisión fundamentales dentro de las corporaciones económicas multinacionales.

10. Badinter, E., XY. La identidad masculina. Trad. Monserrat Casals. Madrid 1993.

11. Gilmore, D., Hacerse hombre: concepciones culturales de la masculinidad. Barcelona 1994.

12. David, D.S. and Brannon, R., The forty-nine percent majority: the male sex role. Massachusetts 1976.

13. Expresión de Helga Dierichs, en Mitscherlich, M. y Dierichs, H., Des Hommes, Des Femmes, 1983. Citado en Badinter, E., XY... p. 161. 
pura e inalterable. Las mujeres son meros accesorios sexuales a los que en ningún caso le une vinculación afectiva. Es un héroe nómada. El único placer que experimenta el pistolero es el del combate; un placer basado en la estética del autocontrol de las emociones, la habilidad para matar y la muerte heroica. Es importante observar que el duelo, como combate entre iguales, proporciona el reconocimiento de la masculinidad; del honor en términos de Bourdieu ${ }^{14}$. Esta forma de reconocimiento se encuentra implícita en la conducta del reto o el enfrentamiento, en la que los héroes se exponen de acuerdo con las expectativas de su masculinidad hegemónica. Badinter observa que los modelos de Rambo o Terminator mantienen la línea del pistolero en una relación ascendente hacia la impasibilidad:

Aunque sea silencioso e impasible, el héroe del western le deja al espectador la posibilidad de adivinar su humanismo, sus conflictos, sus sentimientos y, por tanto, su "debilidad" [...] Aquí radica precisamente la gran diferencia entre él y Rambo o Terminator, que ni tan siquiera tienen ya esas debilidades: al haber sido dotados de una fuerza sobrehumana han conseguido vaciarse de todo sentimiento ${ }^{15}$.

La potencia masculina evoluciona desde la represión de la emotividad hasta la ausencia total de la misma. En este punto, el hombre es todo cuerpo y el cuerpo está absolutamente instrumentalizado para el ejercicio de la violencia ${ }^{16}$. La máquina Terminator se ha liberado de cualquier miedo, dolor o moralidad, lo cual sigue siendo demasiada exigencia para los hombres reales.

Dentro de la mística del hombre duro, pero con un atisbo de mayor humanidad, nos encontramos el personaje de Rocky. Como Rambo, Rocky es protagonizado por el actor de culto Sylvester Stallone. Rocky es un hombre generoso que intenta formar una familia dentro de un entorno social de pobreza y delincuencia, cuando se encuentra con la oportunidad de prosperar económica y profesionalmente como boxeador. Y es aquí donde surge la mística de la masculinidad, con un hombre que se construye a sí mismo mediante el entrenamiento físico para conseguir el éxito. "Constrúyete a ti mismo y triunfarás", o lo que es lo mismo, la masculinidad como personificación de la ideología meritocrática del capitalismo occidental ${ }^{17}$. Por otro lado, Rocky

14. Bourdieu, P., La dominación masculina. Trad. Joaquín Jordá. Barcelona 2005.

15. Badinter, E., XY. La identidad masculina... p. 163.

16. En otro lugar, he señalado la relación entre el autocontrol y la violencia como reversos constitutivos de la masculinidad patriarcal. La represión de la emotividad no sólo hace al hombre impasible frente a sus propias necesidades emocionales, sino también frente los sentimientos y las necesidades de los demás. Es la pragmática del control como condición del poder patriarcal. Véase Sambade, I., "La pragmática masculina del control: del gobierno de sí mismo hacia la violencia contra las mujeres". Nomadías 11 (2010), pp. 42-68.

17. Gil, E., El nuevo sexo débil. Madrid 1997. 
tiene algunas de las características del hombre blando: es tierno, amable y comprensivo con su mujer, quien trabaja en una tienda de animales para mantener a un hermano holgazán. Pero, en la segunda entrega de la saga, Rocky experimenta una fuerte crisis personal cuando deja el boxeo. La pérdida de su rol profesional, germen de su éxito social, le ocasiona una profunda depresión que le empujará a volver al ring, incluso arriesgando su salud, en una nueva muestra de masculinidad.

El hombre blando (soft male) representa al prototipo de masculinidad que ha interiorizado las críticas del feminismo, al tiempo que ha visto a las mujeres desarrollar una energía tradicionalmente calificada como viril. En su obra Iron John, Robert Bly sostiene que el hombre dulce, identificado con el modelo materno, acaba convirtiéndose blando, pasivo y desestructurado ${ }^{18}$. El hombre blando es capaz de sentir como el otro-femenino, pero carece de determinación: se muestra pasivo y aterrado tanto por su propia agresividad, como por su deseo de autoafirmación latente. Para Bly, no es tan siquiera capaz de ejercer el grado de determinación que su madre exhibe de forma natural. Contrariamente, lejos de responsabilizar a la madre, los estudios psicológicos de finales de los años ochenta se centran en la ausencia del padre como causa de la desestructuración del hombre blando ${ }^{19}$. Si bien la nueva economía capitalista comportó una doble exigencia para las mujeres (determinación en la esfera pública y trabajo de cuidado, emocional y material, en la privada $)^{20}$, los padres de clase media trabajadora sólo experimentaron la exigencia de una jornada laboral que lo ausentaba del mismo ${ }^{21}$. Surge así la figura de un padre ausente, medio tirano, medio déspota, educado en el modelo masculino que rechaza la expresión de sus emociones, lo que, frente a la figura de la madre, le priva de toda legitimidad en el hogar. Este modelo de paternidad no supuso un ejemplo a seguir ni en lo que se refiere a la autonomía personal, ni mucho menos en el ámbito afectivo de la filiación paterno-filial. La consecuencia para los hijos fue verse convertidos en hombres con grandes dificultades a la hora de organizar sus objetivos, de reconocer sus necesidades y de expresar sus deseos. Hombres sin determinación, responsabilidad ni iniciativa que necesitan perpetuamente de aquella madre a quien idolatran ${ }^{22}$. Son los Principitos, Perter Pan o Flying Boys, hombres que se resisten a crecer, que confunden sus necesidades emocionales con las sexuales ${ }^{23}$ y tienden a descargar sus responsabilidades afectivas sobre sus parejas ${ }^{24}$. El actor Michael J. Fox, con su

18. Bly, R., Iron John. New York 1990.

19. Badinter, E., XY...

20. Molina, C., Dialéctica feminista de la ilustración. Barcelona 1994.

21. Clare, A., La masculinidad en crisis. Trad. Irene Cifuentes. Madrid 2002.

22. Courneau, G., Père manquant, fils manqué. Québec 1989, citado en Badinter, E., $X Y \ldots$ p. 181.

23. Badinter, E., $X Y \ldots$

24. Marqués, J.V. y Osborne, R., Sexualidad... 
aspecto físico juvenil, interpretó numerosos personajes que representan a eternos Flying Boys.

Es importante destacar que algunos de los cambios ocasionados en la masculinidad como consecuencia de las demandas de las mujeres (como la dulzura y el trato amable hacia éstas) se integraron en los modelos hegemónicos de masculinidad, ocasionando una cierta dulcificación de los mismos. Este es el caso de los héroes románticos, aquellos hombres que Ilegan a la vida de las mujeres para salvarlas con su amor verdadero, reproduciendo una división sexual de funciones en las que ellos ostentan el prestigio social y económico, mientras que ellas se ven relegadas a un espacio doméstico en el que ven controlados su cuerpo y su sexualidad ${ }^{25}$. El actor Richard Gere protagonizó numerosos filmes románticos durante las décadas de los ochenta y los noventa, convirtiéndose en un icono de esta masculinidad romántica heterosexual ${ }^{26}$.

El héroe romántico hetero ha experimentado una peligrosa redefinición en las proyecciones audiovisuales de esta última década. Los protagonistas masculinos encarnan personajes con conductas absolutamente antisociales (Tres metros sobre el cielo -Fernando González Medina, 2010), monstruos devoradores de mujeres (Crepúsculo- Catherine Hardwicke, 2008) y sádicos dominadores sexuales (50 sombras de Grey - Sam Taylor Wood, 2015). El caso más significativo, dada su cercanía con la realidad social, podría ser el de Hache, protagonista masculino de $A$ tres metros sobre el cielo. Hache ejerce sobre su amada todo tipo de conductas delictivas (acoso, rapto, intimidación, allanamiento de morada) que esta acaba asimilando hasta caer enamorada de su héroe. Es difícil no observar una legitimación de la violencia de género en este relato. Hache es disculpado en última instancia porque todo lo que hace, lo hace por amor. La cultura del amor romántico termina funcionando, de este modo, como una estructura de socialización en la desigualdad y la violencia de género.

Desde nuestra perspectiva, esta dulcificación de los modelos violentos de masculinidad sólo puede entenderse como una contra-reforma patriarcal, tal y como ha sido denominada por algunas pensadoras feministas ${ }^{27}$. Esta revancha se caracteriza por el empleo de un poder mucho más sutil que tiende a pasar desapercibido; el poder de definición de los medios de comunicación de ma$\operatorname{sas}^{28}$, poder que sigue estando mayoritariamente en manos de hombres. Nos encontramos así con la perfecta realización del patriarcado de consentimiento tal y como ha sido definido por Alicia Puleo ${ }^{29}$ : una sociedad donde los estereotipos de género son representados como atractivos y deseables por los medios

25. Herrera, C., La construcción socio-cultural del amor romántico. Madrid 2011.

26. Salazar, O., La igualdad en rodaje: masculinidades, género y cine. Valencia 2015.

27. De Miguel, A. Neoliberalismo sexual. El mito de la libre elección. Madrid 2015.

28. Sambade, I. y Torres, L., "Cuerpo e identidad de género en la sociedad de la información", Puleo, A. (ed.), Ecología y género en diálogo interdisciplinar. Madrid 2014, pp. 65-80.

29. Puleo, A. H., "Patriarcado"... 
de comunicación de masas, generando así el deseo de identificación en mujeres y hombres que, de esta manera, reproducen roles y conductas que perpetúan la sujeción masculina de las mujeres.

Otros ejemplos de masculinidad hiperviril, de hombres duros, aparecieron durante los años setenta, dentro de determinadas subculturas gay como los bear o los leather. De hecho, ambas subculturas gay fueron visibilizadas y normalizadas en el imaginario cultural occidental como consecuencia de su representación en el cine hollywoodiense de esta década. Su popularización conllevó la normativización del modelo de hipervirilidad entre los hombres homosexua$\mathrm{les}^{30}$, frente a la denostación del modelo afeminado. Esta tendencia se confirmó entre los actores del porno gay, quienes anticiparon un modelo estético de masculinidad que, según Mark Simpson, se ha generalizado y convertido en el actual modelo hegemónico de belleza masculina, independientemente de la orientación sexual: el modelo del spornosexua ${ }^{\beta 1}$.

Elisabeth Badinter ha apuntado que, en última instancia, la fascinación homosexual por los modelos de hipervirilidad entraña una reproducción de los modelos patriarcales de masculinidad, con sus violencias y su desprecio por las mujeres y la femineidad ${ }^{32}$. Análogamente, Javier Sáez también advierte el peligro de la normativización del modelo homosexual de hipervirilidad:

Su parecido a la cultura heterosexual dominante hace que a veces se caiga en la tentación de recuperar el discurso plumófobo y normativo. Algunas corrientes de la cultura del cuero y de los osos son profundamente plumófobas (además de misóginas y lesbófobas), acusan a las locas de dar una imagen ridícula de los gays, y reivindican una masculinidad "normal" e integrada que busca la aceptación del colectivo heterosexual ${ }^{33}$.

Además, no parece que esta normativización haya comportado la plena aceptación de los hombres homosexuales por parte de sus iguales hetero: "pasarse al enemigo no calma la cólera. Los homosexuales del cuero se han convertido en diana de las bandas de jóvenes homófobos" ${ }^{\prime \prime 4}$.

30. Badinter, E., $X Y \ldots$

31. Simpson, M., "Sporno". Marksimpson.com (2010), Consulta 21 junio 2017 (http:// www.marksimpson.com/blog/2010/04/17/sporno/).

32. Badinter, E., XY... p. 193.

33. Sáez, J., "Excesos de la masculinidad: la cultura leather y la cultura de los osos", Grupo de trabajo Queer (ed.), El eje del mal es heterosexual. Figuraciones, movimientos y prácticas feministas queer. Madrid 2005, pp. 137-148, p. 146.

34. Kleinberg, S., "The new masculinity of gay men and beyond: Where have all the sissies gone?", Kimmel, M. y Messner, M. A. (eds.), Men's lives. New York 1978/1989, pp. 101114. p. 109. 
En este punto, hemos podido comprobar que la construcción física del cuerpo conforme a la apariencia de hipervirilidad permanece constante a lo largo de diversos modelos de masculinidad. En este sentido, podemos observar cómo, redefinidos por la cultura de consumo gay, los modelos de hipervirilidad basados en la construcción física del cuerpo evolucionaron hasta convertirse en modelos hegemónicos de masculinidad basados en el concepto de belleza. Es decir, los hombres comenzaron a posicionarse como objetos del deseo en un proceso de aparente feminización.

A mediados de los noventa, Mark Simpson acuñó el concepto de metrosexual para definir a un hombre de la sociedad urbana post-industrial que se preocupa por su imagen y se posiciona como un objeto de deseo, a partir del cuidado estético de sí mismo y de un estilo de vida sofisticado, definido por las tendencias de consumo propuestas desde la moda masculina ${ }^{35}$. El metrosexual no es un hombre afeminado conductualmente. Su supuesta feminización se origina en que se dedica a construir su imagen a través del consumo de moda masculina. Es un narcisista cuya intención es ser mirado, deseado, para así poder saber que existe. El metrosexual se ha tomado a sí mismo como su propio objeto de amor y placer. Este modelo de masculinidad surgió originariamente en la cultura gay, pero, posteriormente, se generalizó con independencia de la orientación sexual. Para Simpson, David Beckham es el icono de la metrosexualidad.

A pesar de la desvinculación del metrosexual con cualquier tipo de orientación sexual, los sectores conservadores de la cultura de consumo proyectaron un modelo alternativo de belleza masculina ${ }^{36}$. Aparece así el übersexual; un hombre que se preocupa por su apariencia, pero que construye su imagen con elementos propios de la masculinidad tradicional (pelo en el pecho, barba aparentemente descuidada, trajes oscuros de corte clásico, etc.). Este modelo es el producto de una tendencia heterocéntrica de mercado que pretende captar como consumidores a los hombres que rechazan la metrosexualidad, pero no pueden permanecer ajenos a la generalización de las prácticas de cuidado estético de sí mismos. George Clooney es su máximo representante.

Tanto el modelo el metrosexual como el übersexual son modelos que requieren de una construcción física del cuerpo. De hecho, Beckham es un deportista profesional. Su complexión es atlética, pero estos modelos de belleza pueden ser encarnados por hombres con diferentes grados de desarrollo muscular. En cambio, el modelo del spornosexual representa a un hombre de grandes dimensiones musculares, un hombre de morfotipo atlético hipertrófico, originariamente representado por modelos de hipervirilidad como los personajes de

35. Simpson, M., "Meet the metrosexual". Salom.com (2002). Consulta 22 de junio de 2017 (http://www.salon.com/2002/07/22/metrosexual/).

36. Saltzman, M., Matathia, I. and O'Reily, A., The future of man: the rise of übersexual and what he means for marketing today. New York 2005. 
Rambo o Terminator ${ }^{37}$. El término "spornosexual" es una contracción de los términos sportman, porno y sexual ${ }^{38}$. Mark Simpson acuña el concepto para referirse a hombres heterosexuales que construyen su cuerpo con una intención homoprovocativa. De hecho, encuentra el origen de este modelo en los actores del cine gay clásico. Este modelo ha resignificado la nueva metrosexualidad. Así, el cuerpo de masa muscular hipertrófica, los tatuajes y la actitud narcisista definen a los hombres modernos que desean ser deseados. El icono de la spornosexualidad es el actor australiano Chris Hemsworth.

\section{Los nuevos modelos de representación de las masculinidades: androcentris- mo y urdimbre patriarcal}

Es importante observar que los modelos de belleza masculina están fuertemente influenciados por las tendencias gay. Este hecho tiene múltiples significaciones susceptibles de ser valoradas. En primer lugar, es posible que signifique una legitimización de la libertad de las personas homosexuales, de los hombres en particular, lo cual implicaría a su vez una cierta deconstrucción del imperativo heterosexual de los patriarcados occidentales. De hecho, la visibilización actual de los colectivos LGTBIQ+ apunta en esta misma dirección. Pero, por otra parte, no podemos olvidar que estos modelos se han generalizado y heterosexualizado desde una cultura de consumo que pondera los intereses comerciales por encima de la transformación social ética ${ }^{39}$. De este modo, la definición de los modelos de belleza masculina sigue siendo fundamentalmente androcéntrica.

Un elemento que muestra claramente el androcentrismo inherente a los modelos de belleza masculina es que todos ellos, más allá del cuidado de la imagen centrado en la cultura de consumo, se basan en la construcción física del cuerpo. Todo tipo de personajes masculinos (héroes épicos, héroes bélicos, héroes románticos, anti-héroes, etc.) se caracterizan por un morfotipo atlético o atlético hipertrófico que expone socialmente la construcción física de sí mismo realizada por el sujeto masculino. Incluso en el caso de personajes representados desde el perfil del hombre blando, podemos encontrarnos con una masculinidad basada en la construcción del cuerpo: "cuanto más frágil por dentro se siente un hombre, más intenta crearse un caparazón exterior que compense..." 40 .

37. Sambade, I., "La construcción social del cuerpo masculino: género, salud y conducta antisocial", Género y salud en Cifras, 14(3), México 2017, pp. 6-18.

38. Simpson, M., "Objectify yourself. Why straight young men crave gay adulation". OUT (2015). Consulta 18 junio 2017 (http://www.out.com/entertainment/2015/01/06/objectify-yourself-why-straight-young-men-crave-gay-adulation).

39. Salazar, O., La igualdad en rodaje...

40. Courneau, G., Père manquant... p. 40. 
La vinculación de los modelos de belleza con las prácticas de disciplinamiento físico pone de manifiesto la cultura patriarcal sobre la que se asientan. Si buscamos los precedentes históricos de los modelos de belleza basados en la construcción de cuerpo, nos encontramos con que el morfotipo atlético, con su variante hipertrófica en la actualidad, ha sido el canon hegemónico de belleza masculina desde la antigüedad clásica hasta nuestros días ${ }^{41}$. En la antigüedad clásica, los hombres disciplinaban su cuerpo para proteger a la polis en caso de guerra, de modo que, a través de la protección del Estado, obtenían la condición del honor. El honor ha legitimado históricamente el estatus de ciudadanía de los hombres y su posición de control del capital social y del capital simbólico, mientras que posicionaba a las mujeres, en cuanto objetos, en el orden de la apariencia y del prestigio del núcleo familiar ${ }^{42}$. Por lo tanto, el ejercicio de la violencia en la representación y la defensa del Estado y de las personas que viven en el mismo ha sido uno de los principales mecanismos de legitimación de la supremacía masculina. Esta estructura de poder-protección se reproducía asimismo en el hogar, en el que cada hombre era dueño y protector de su mujer y sus hijas e hijos. En síntesis, la posición social de los hombres implicaba como contrapartida la exigencia moral de la protección del hogar y la patria. Por este motivo, los hombres han sido históricamente preparados para la guerra a través de la construcción del cuerpo y de su socialización en la cultura de la violencia ${ }^{43}$.

Esta mística masculina que define el cuerpo masculino como un instrumento para la violencia se ve exaltada en la abundante representación de héroes épico-bélicos dentro de la producción cinematográfica mundial, especialmente la norteamericana. Es más, tanto héroes como antihéroes se ajustan a los cánones de belleza del hombre fuerte y duro. Y también ambos personajes se muestran libres en el ejercicio de la violencia. De hecho, en la representación cinematográfica, no es tan importante la condición moral personaje como su papel en el relato ${ }^{44}$. El protagonismo de un personaje antisocial hace que el espectador empatice con éste, sobre la base de su común cultura androcéntrica. Obsérvese,

41. López, M. y Gauli, J. C., "El cuerpo imaginado". Revista Complutense de Educación 11 (2) (2000).

42. Bourdieu, P., La dominación masculina...

43. Los hombres occidentales siguen siendo socializados en el juego de la guerra a pesar de que la militarización estatal ha desaparecido. Si bien el juego de la guerra ha perdido su lugar en las calles, en la actualidad, tanto niños como adultos mantienen competiciones en Internet con juegos de tal realismo que altera el estado psicológico de los participantes.

44. El protagonismo masculino de las películas es una constante trasnacional que se correlaciona con el desproporcionado porcentaje mayoritario de directores y productores frente a directoras y productoras. Este dato lo confirma el estudio financiado por el Instituto Geena Davids. Véase Smith, S., Choueiti, M. and Pieper, K., Gender Inequality in Popular Films: Examining On Screen Portrayals and Behind-the-Scenes Employment Patterns in Motion Pictures Released between 2007-2013, USC Annenberg and Media, Diversity, \& Social Change Initiati- 
desde esta perspectiva, que los anti-héroes del discurso cinematográfico también tienen su propio código de honor. Como ha señalado Celia Amorós, a través de su construcción práctica en los procesos de autodesignación, la masculinidad homologa a los hombres como iguales respecto de las mujeres, quienes se ven coartadas a construir su identidad en la heterodesignación patriarcal ${ }^{45}$. De manera análoga, pero desde un enfoque sociológico, Raewyn Connell, ha explicado que la violencia masculina entre hombres es una práctica de confirmación de la masculinidad, en un sistema en el que la lucha por la hegemonía entre diversos colectivos sociales de hombres hace de todos ellos cómplices de la discriminación de las mujeres ${ }^{46}$. Es más, Connell apunta que la masculinidad hegemónica suele respaldar la legitimidad social del patriarcado, lo que da lugar a otro tipo de violencia masculina: aquella que algunos hombres ejercen contra las mujeres para mantenerlas en un estado de subordinación e injusticia; la violencia de género.

El morfotipo atlético es también el canon de belleza que encarnan los deportistas profesionales a través de su participación en el discurso publicitario. Norbert Elías ha explicado que, en las modernas sociedades occidentales, los deportes competitivos de equipo se han convertido en un símbolo subliminal de la guerra al que trascienden sus valores ${ }^{47}$. En esta línea de pensamiento, Badinter ha apuntado la analogía existente entre los modelos deportivos de masculinidad y los modelos de hipervirilidad como los personajes de Rambo o Terminator, ambos sujetos de acción bélica y violencia ${ }^{48}$. De este modo, los deportes competitivos de equipo constituyen todo un espacio de socialización en la masculinidad patriarcal. Primero, convierten a los deportistas profesionales en los modelos de virilidad de millones de niños en el mundo a través de su representación tanto deportiva como publicitaria. En segundo lugar, constituyen un verdadero disciplinamiento del cuerpo y de la emotividad cargado de connotaciones andocéntricas. De este modo, si nos acercamos a un campo de fútbol, no es muy difícil escuchar a entrenadores de niños de siete años de edad, diciéndoles que tienen que aguantar el dolor si no quieren "jugar como niñas". Esta forma de estoicismo masculino se fragua en la concepción mecanicista del cuerpo, según la cual éste es una herramienta, incluso una máquina, que se emplea conseguir nuestros objetivos.

El androcentrismo constitutivo de los modelos de belleza masculina se percibe con mucha más claridad si su análisis se compara con el de los modelos de belleza femenina. Desde este enfoque, Pilar López ha señalado que el mo-

\footnotetext{
ve supporters 2014. Fátima Arranz ha realizado un estudio análogo sobre el cine español con resultados muy similares. Véase Arranz, F., Cine y género en España. Madrid 2010.

45. Amorós, C., La gran diferencia...

46. Connell, R.W., Masculinities...

47. Elías, N. y Dunning, E., Deporte y ocio en el proceso de la civilización. Madrid 1992.

48. Badinter, E., $X Y$...
} 
delo normativo de belleza femenina es representado fundamentalmente por el morfotipo ectomorfo extremo ${ }^{49}$. Este modelo remite al estereotipo tradicional de la femineidad como debilidad esencial, estereotipo complementario con una masculinidad hegemónica definida en torno a la protección y la salvación de los personajes femeninos. Ahora bien, tal y como explicó Vicent Marqués, la protección de las mujeres que se ejerce desde la supremacía social es en realidad una forma de sobreprotección que termina limitando su autonomía ${ }^{50}$.

Pilar López explica asimismo que el modelo ectoformo coexiste con una representación altamente sexualizada de la mujer que responde al placer de la mirada masculina ${ }^{51}$. Es, por lo tanto, una representación androcéntrica de la femineidad que, no sólo seduce a las mujeres para que aprendan a mirarse a sí mismas como objetos desde las proyecciones masculinas, sino que induce a los hombres a posicionarse como "observadores objetivantes" 52 . Un ejemplo del androcentrismo de los modelos de belleza femenina lo encontramos en un modelo de femineidad aparentemente novedoso: las heroínas. Las heroínas son personajes femeninos que han transgredido normas tradicionales del patriarcado, en particular la de que las mujeres no pueden ejercer violencia. Ahora bien, las heroínas no son percibidas como una amenaza dentro del imaginario patriarcal porque su cuerpo hipersexualizado no deja de representar una sexualidad controlada por los hombres ${ }^{53}$.

Natasha Walter ha estudiado las consecuencias de la hipersexualización del modelo de femineidad en su obra Muñecas vivientes ${ }^{54}$. Walter explica que el modelo hipersexualizado de femineidad aparece en un momento de apariencia de igualdad de género para hacer creer a las mujeres que sólo pueden obtener poder social a través de la sexualización de su cuerpo. El poder de las mujeres reside en su sexualidad, eso sí, ahora bajo la soflama de que son ellas quienes, libremente, deciden utilizarlo. Pero la realidad es que a la hipersexualización de los modelos de femineidad le subyacen los intereses de la industria del sexo; un mercado regentado fundamentalmente por hombres y dirigido hacia su propio placer. Lejos de proporcionar éxito y ascenso social para las mujeres, este

49. López, P., Bengoechea, M., Díaz-Aguado, M. J. y Falcón, L., "Representación, estereotipos y roles de género en la programación infantil 1", Infancia, televisión y género. Guía para la elaboración de contenidos no sexistas en programas infantiles de televisión. Madrid 2005.

50. Marques, J.V. y Osborne, R., Sexualidad...

51. López, P., Bengoechea, M., Díaz-Aguado, M. J. y Falcón, L., "Representación...

52. Femenías, M.L., "Violencia de sexo-género. El espesor de la trama", Laurenzo, P., Maqueda, M.L. y Rubio, A. (eds.) Género, violencia y derecho. Valencia 2008, pp. 61-88. p. 74.

53. Ruthven, A., "La violencia sexuada en los cómics. ¿Quién salvará el mundo?", Martín Lucas, B. (ed.). Violencias (in)visibles. Barcelona 2010, pp. 161-176.

54. Walter, N., Muñecas vivientes. El regreso del sexismo. Trad. María Álvarez Rilla. Madrid 2010. 
modelo está ocasionando cotas de explotación sexual de las mismas jamás antes conocidas. No parece fortuito que en este caso los hombres no sean representados, que no sean los sujetos del relato. Más bien, nos encontramos con una estrategia que oculta su responsabilidad en la reproducción de un modelo transnacional de trata y prostitución de mujeres, entre ellas mujeres menores de edad ${ }^{55}$.

Otra de las características que diferencia significativamente los modelos de belleza femeninos de los masculinos es la fragmentación del cuerpo femenino. La representación de las mujeres a través de las partes más erotizadas de su cuerpo y en ausencia del rostro es una forma de objetualización sexual que les desprovee de toda su singularidad como personas ${ }^{56}$. Por el contrario, los desnudos masculinos suelen realizarse a través de planos completos o americanos en los que siempre amarece el rostro del personaje ${ }^{57}$. El personaje masculino no pierde su subjetividad, no es un objeto sexual. En el peor de los casos, es un sujeto que desea ser deseado.

Los modelos de representación masculina representan siempre al sujeto del relato socialmente compartido ${ }^{58}$. Hombres duros, héroes románticos, personajes históricos, deportistas en spots publicitarios, asesinos en serie, gánster, etc., todos ellos son los protagonistas de los relatos en los que aparecen. Incluso en los informativos de radio y televisión, los hombres aparecen tres veces más que las mujeres ${ }^{59}$. Además, mientras que éstos son representados en función de su actividad en la esfera social pública, las mujeres lo siguen siendo principalmente en función de su estatus vicario ${ }^{60}$. Se produce así una infrarrepresentación de las mujeres que detentan posiciones de autoridad en la esfera social, mujeres que representan avances sociales en igualdad, frente a la sobre-representación de hombres con poder. Se reproduce así el sesgo androcéntrico que representa a los hombres y lo masculino como superior y más valioso, induciendo en los mismos la idea de que, frente a las mujeres, ellos son los sujetos de la esfera social pública. Una consecuencia de esta forma de androcentrismo es que aquellos hombres que se sientan fuertemente identificados con el modelo hegemónico de masculinidad experimentarán malestar y frustración frente a mujeres con posiciones que impliquen autori-

55. Sambade, I., "La instrumentalización de la sexualidad. Masculinidad patriarcal, pornografía y prostitución", De Miguel, A. y Nuño, L. (eds.), Elementos para una teoría crítica del sistema prostitucional. Granada 2017, pp. 169-180.

56. Yrache, L., "Imagen de la mujer y el hombre en publicidad", Plaza, J. y Delgado, C. (Eds.), Género y comunicación. Madrid 2007, pp. 101-128.

57. Yrache, L., "Imagen de la mujer...

58. Aguilar, P., "El cine, una representación patriarcal del mundo", Plaza, J. y Delgado, C. (eds.), Género y comunicación. Madrid 2007, pp. 129-148.

59. López, P., $2^{\circ}$ informe de la investigación: representación de género en los informativos de radio y televisión. Madrid 2006.

60. López, P., $2^{\circ}$ informe de la investigación... 
dad o autonomía en la esfera social, más incluso si éstas son sus compañeras emocionales.

La representación de los hombres en la esfera social pública presupone la racionalidad de sus actos. Se perpetúa así otra característica tradicional de la masculinidad patriarcal moderna: la identificación entre Razón y masculinidad ${ }^{61}$. Obviamente, la racionalidad que entra en juego en estos relatos es la racionalidad instrumental, pues sólo desde este tipo de racionalidad se pueden justificar conductas antisociales y violentas, atendiendo no tanto a los medios como a los fines. En todo caso, esta representación reproduce la lógica patriarcal moderna, según la cual lo masculino se asocia con la Razón y la Cultura, significando la superioridad frente a una femineidad identificada con la emotividad y la Naturaleza ${ }^{62}$. La consecuencia es la concepción de una masculinidad racional auto-engendrada, una masculinidad que emerge de la razón pura, rompiendo sus vínculos biológicos con la madre, símbolo de la femineidad originaria, en un acto de autogénesis ${ }^{63}$. De este modo, la identificación entre masculinidad y Razón no sólo justifica y excusa las acciones de los sujetos del relato, sino que también genera un sentimiento de minusvaloración y odio de lo femenino y las mujeres; genera misoginia.

En síntesis, los modelos de representación de la masculinidad y la femineidad no sólo son diversos, sino también socialmente desiguales. Por lo tanto, bajo el espejismo de igualdad vigente, la representación audiovisual de las identidades de género sigue normalizando la supremacía social de los hombres a partir de la asimetría fundamental de poder entre el sujeto (masculinizado) y el objeto (feminizado).

\section{Prácticas sociales masculinas}

Hemos visto cómo los modelos de masculinidad se caracterizan por la representación de hombres que han disciplinado tanto su cuerpo como su emotividad. Estas características les identifican como los sujetos del relato socialmente compartido, los sujetos de la acción en la esfera social pública, frente las mujeres. Éstas siguen siendo representadas según una femineidad androcéntrica que, a partir de su identificación con la Naturaleza, o bien las sitúa en la esfera social privada, o bien las objetiviza de acuerdo al deseo sexual y la mirada masculina. Por el contrario, la mera presencia de los modelos de masculinidad en la esfera social pública les confiere la condición racional que a los hombres se les presupone. De este modo, la masculinidad hegemónica se representa como la negación de cualquier tipo de naturaleza (femineidad); una operación lógica

61. Seidler, V., La sinrazón masculina. México 2000.

62. Plumwood, V., Feminism and the Mastery of Nature. London and New York 1993.

63. Amorós, C., Hacia una crítica de la razón patriarcal. Barcelona 1985. 
cuyo correlato pragmático implica como condición sine qua non el ejercicio masculino de autocontrol del cuerpo y las emociones ${ }^{64}$.

Inculcadas a lo largo de la socialización patriarcal masculina, las prácticas de autocontrol del cuerpo y de la emotividad preparan y disponen a los hombres para desenvolverse en los juegos de poder de la esfera social pública. Es el desarrollo de la condición racional que se les presupone y que justifica su posición de poder social. Es lo que se ha denominado pragmática masculina del control ${ }^{65}$. Y puesto que su racionalidad está fuera de toda duda, las prácticas sociales de los hombres se encuentran dispuestas para demostrar su virilidad (la cual siempre está puesta en entredicho) como condición definitoria de aquellas personas que ostentan la supremacía social. Este es el motivo por el cual la razón exhibida por los hombres como sujetos de la esfera social pública es una razón netamente instrumental, más allá de las posibles connotaciones éticas de sus acciones ${ }^{66}$. El control racional del cuerpo y las emociones posibilita el desarrollo de aquellas acciones determinadas conforme a los fines racionalmente elegidos: el éxito social, la defensa de la patria, la consecución de la victoria, la protección de la mujer deseada, etc. Ahora bien, la definición instrumental de la razón es también la causa de que la confirmación de la masculinidad requiera de la instrumentalización del propio cuerpo y la emotividad.

La instrumentalización del cuerpo y de la emotividad se pueden observar en la moral del honor, puesto que, como señala Bourdieu, ésta se traduce en la disposición corporal hacia el enfrentamiento; en el acto de mirar a la cara al «adversario» con una postura rígida y firme, garante de seguridad y valentía ${ }^{67}$. En resumidas cuentas, una postura fruto del autocontrol del cuerpo y de la emoción del miedo. Bourdieu explica también que esta disposición se debe a que la moral del honor se fragua en las actividades de representación social que los hombres realizan en los juegos sociales, de los cuales la guerra es el juego por excelencia.

La abundante representación audiovisual de hombres de honor es una muestra clara de que esta moral androcéntrica sigue teniendo vigencia a pesar del rechazo de la violencia que exige la condición democrática de las modernas sociedades occidentales. Asimismo, la vigencia de la moral androcéntrica del honor, con su exaltación de la violencia y su disciplinamiento del cuerpo y de

64. Sambade, I., "La pragmática masculina del control: del gobierno de sí mismo hacia la violencia contra las mujeres". Nomadías 11 (2010), pp. 42-68.

65. Sambade, I., "La pragmática...

66. Sambade, I., "Sobre las contradicciones de la razón moderna y la constitución de la subjetividad masculina", en Prisma Social. Revista de Ciencias Sociales [En línea], no 13 (2014), pp. 787-851. Disponible en internet: http://www.isdfundacion.org/publicaciones/revista/ numeros/13/secciones/abierta/a_08_subjetividad_masculina.html.

67. Bourdieu, P., La dominación masculina... 
la emotividad de los hombres, ofrece una explicación certera sobre el protagonismo masculino de la conducta antisocial. Tanto la cultura del riesgo como la disposición hacia la violencia de los hombres son expresiones una cultura androcéntrica del honor que permanece latente bajo la ficción de igualdad que genera el discurso políticamente correcto. Las peleas callejeras, las carreras de motocicleta, la falta de seguridad laboral, la violencia contra las personas, la violencia sexual contra mujeres y niños, el tráfico y consumo de drogas, el tráfico de armas, etc., son todas ellas actividades ejercidas principalmente por hombres ${ }^{68}$.

La cultura masculina del riesgo se origina en la concepción de la masculinidad como dureza física y emocional (el hombre duro), y requiere de la instrumentalización del cuerpo y de la emotividad, entendidos como naturaleza animal a domeñar por el sujeto racional que representa la Cultura. De este modo, las sensaciones originadas en el cuerpo como el dolor o la aprehensión serán desestimas como fuente de conocimiento ${ }^{69}$. Estas emociones son consideradas como un síntoma de debilidad, condición esencial de la femineidad en la cosmología patriarcal, lo que exige a los hombres una recurrente confirmación de su masculinidad:

Como hombres aprendemos a tratar nuestro cuerpo como algo aparte, como algo que necesita ser entrenado. Muchas veces exigimos más de nosotros mismos porque intentamos ponernos a prueba frente a los límites del cuerpo, y esto constituye una forma de afirmar nuestra masculinidad $^{70}$.

La masculinidad se demuestra sometiendo el cuerpo y subestimando sus límites. Las sensaciones del cuerpo y las emociones que en él se originan deben ser reprimidas, puesto que los límites de cuerpo son percibidos como falta o carencia de masculinidad. En consecuencia, la cultura masculina del riesgo se concreta en una constante disposición hacia la acción (como forma de confirmación de la masculinidad) y en el sentido de invulnerabilidad del cuerpo. Éste se convierte así en el objeto central de la cultura masculina del riesgo: trabajar sin las medidas de seguridad adecuadas, exponerse físicamente cuando uno se encuentra enfermo, consumir alcohol en demasía, tener relaciones sexuales esporádicas sin protección profiláctica, conducir a velocidades extremas, etc.,

68. Clare, A., La masculinidad en crisis... Esta aseveración de Clare se cumple también en nuestro Estado. Véase INE. Productos y Servicios / Publicaciones / Publicaciones de descarga gratuita / Mujeres y hombres en España / Delito y violencia (actualizado 24 enero 2017) / 7.1 Personas condenadas. Consulta 29 de junio de 2017 (http://www.ine.es/ss/Satellite?L=es_ES\& $\mathrm{c}=$ INESeccion_C\&cid=1259925505456\&p=1254735110672\&pagename=ProductosYServicios \%2FPYSLayout\&param1=PYSDetalle\&param3=1259924822888).

69. Seidler, V., La sinrazón masculina...

70. Seidler, V., La sinrazón masculina... p. 45. 
son todas acciones comúnmente practicadas por los hombres (machadas), en las que el cuerpo e incluso la vida son puestas en peligro.

Una de las conductas de riesgo íntimamente relacionadas con la construcción física del cuerpo ha aparecido junto a hegemonía del morfotipo atlético hipertrófico como modelo de belleza basado en la hipervirilidad. Nos referimos al consumo de esteroides anabolizantes androgénicos $(E A A)^{71}$.

La representación de héroes y superhéroes por parte de culturistas profesionales (bodybuilders) como Arnold Schwarzenegger normalizó el canon estético del culturista como modelo de hipervirilidad. De este modo, los jóvenes comenzaron a practicar bodybuilding para conseguir la imagen física de sus modelos de masculinidad. Pero con la práctica del bodybuilding se normaliza también el consumo de EAA entre los hombres, incluidos los adolescentes.

Los EAA son hormonas sintéticas que consumidas junto a substancias coadyuvantes como la insulina favorecen un rápido y exponencial aumento del volumen, la potencia y la definición muscular entre sus efectos deseables. Por el contrario, su consumo entraña toda una serie de problemáticas para la salud que abarca desde trastornos conductuales y psicológicos como la vigorexia (dismorfia muscular), hasta graves afecciones viscerales y sistémicas como el cáncer $^{72}$. De hecho, el consumo libre de EAA es actualmente ilegal en la mayoría de los países occidentales. Ahora bien, a pesar de su ilegalidad, múltiples estudios sociológicos realizados recientemente en EEUU muestran que el consumo de EAA ha aumentado entre la población general y que la principal motivación de sus consumidores es más bien estética que deportiva ${ }^{73}$.

Del mismo modo que muchos científicos siguen encontrando en la testosterona una explicación biologicista de la agresividad de los hombres, muchos investigadores han señalado el aumento de las conductas de riesgo como una de las consecuencias del consumo de $\mathrm{EAA}^{74}$. Contrariamente, Middleman sostiene la hipótesis de que el consumo de EAA es parte de un "síndrome de conductas de riesgo" más que una conducta aislada ${ }^{75}$. La consideración seria de suicidio, la exposición a enfermedades de transmisión sexual, la no utilización del cinturón de seguridad, las carreras de motocicletas, la conducción tras el

71. Yesalis, C.E., Courson, S.P., Wright, J., "History of anabolic steroid use in sport and exercise", Yesalis, C.E. (ed.), Anabolic steroids in sport and exercise. 2nd edition. Champaign 2000, pp. 51-71.

72. González, J.M., "Uso y abuso de esteroides anabolizantes". Osasunaz 8 (2008), pp. 185-197.

73. Parkinson, A.B. and Evans, N.A., "Anabolic androgenic steroids: a survey of 500 users", Med Sci Sports Exerc 38(4) (2006), pp. 644-651.

74. Khun, C., Swartzwelder, S. y Wilson, W., Anabolizantes, estimulantes y calmantes en la práctica deportiva. Barcelona 2003.

75. Middleman, A.B. et al., "High-risk behaviors among high school students in Massachusetts who use anabolic steroids". Pediatrics 96 (1995), pp. 268-272. 
consumo de alcohol, la portación de armas y las peleas son, entre otras, conductas de riesgo desarrolladas por hombres que también consumen EAA. Este "síndrome de conductas de riesgo" pone de relieve la significación que los factores culturales como la socialización de género tienen para la conducta de los hombres. De hecho, estas conductas suponen un intento constante de confirmar la masculinidad a través de prácticas que subestiman los límites del cuerpo en relación con la norma patriarcal que exige que los hombres sean valientes. Es decir, que repriman su miedo e instrumentalicen su cuerpo. En este sentido, la propia noción de "construcción del cuerpo" (bodybuilding) implica la acción de un sujeto que se significa a sí mismo como ser racional y a su cuerpo como materia a modelar conforme a determinados fines.

Por otra parte, Middleman observa que los hombres que consumen EAA duplican porcentualmente las conductas de riesgo mencionadas ${ }^{76}$. De una parte, este hecho confirma la hipótesis de que la relación entre los niveles de testosterona y los de agresividad no es de causalidad sino de correlación, lo que, en ningún caso, pone en entredicho el significativo peso de los factores socioculturales en su desencadenamiento ${ }^{77}$. De la otra, nos alerta sobre las dramáticas consecuencias en que puede derivar el consumo de EAA por parte de hombres con una cultura del riesgo.

Las conductas de riesgo mencionadas se caracterizan por un desprecio de los peligros que atentan contra la propia persona, pero también por una transgresión de las normas que puede poner en peligro la integridad física de otras personas. Se confirma así la idea de que, estructuradas a través de la socialización de género, las prácticas masculinas de autocontrol tienen como objetivo el control del Otro-mujer ${ }^{78}$. La violencia es el reverso dialéctico de las mismas, un recurso culturalmente legitimado a través de la definición de la masculinidad para que los hombres pueden confirmar su identidad de género a través del control de las mujeres y del juego del enfrentamiento entre iguales.

El disciplinamiento del cuerpo y de las emociones como pragmática de socialización en la masculinidad hegemónica supone un proceso profundo de enajenación emocional para los hombres ${ }^{79}$. El control y la represión de las emociones que las formas hegemónicas de masculinidad conllevan se pueden confirmar en el prejuicio común de que un hombre ha de ser capaz de aceptar los acontecimientos traumáticos de la vida ("Ser lo bastante hombre para aceptar"). Aceptar los acontecimientos injustos, las vejaciones y las miserias que la vida social patriarcal implican es una de las condiciones de la masculinidad hege-

76. Middleman, A.B. et al., "High-risk behaviors...

77. Darbra Marges, S. y Martí-Carbonel, S., "Psicobiología de la conducta antisocial", Fisas, V., El sexo de la violencia. Barcelona 1998, pp. 43-60.

78. Sambade, I., "La pragmática masculina...

79. Sambade, I., "Sobre las contradicciones... 
mónica que genera la posibilidad de ostentar poder social; el "poder poder"80, en palabras de Celia Amorós. El varón que sea capaz de aceptar los acontecimientos será un hombre duro; alguien que ha aprendido a minimizar el dolor y los daños emocionales. Esta forma de estoicismo masculino genera la sensación de que la situación se tiene bajo control, con lo que nuestra masculinidad no se ve momentáneamente amenazada. Pero es evidente que una represión tamaña de las emociones sólo puede provocar múltiples frustraciones. Estas frustraciones se resuelven sistemáticamente a través del control de las mujeres por varios motivos. En primer lugar, porque la simbología patriarcal las presenta como personas débiles e inferiores que proteger/controlar. En segundo, porque las mujeres tienen las mismas expectativas sociales sobre los hombres que ellos mismos (aquellas que la cultura patriarcal les induce), de modo que éstas pueden pasar a personificar las exigencias del sistema, siendo así culpabilizadas por ello y ubicadas como terreno sobre el que proyectar-resolver las frustraciones masculinas $^{81}$. Y, en tercer lugar, porque el disciplinamiento físico y emocional que supone la masculinidad reduce la capacidad de empatía de los hombres, más aun cuando se trata de aquellas personas que simbolizan valores negados para la masculinidad (ternura, dulzura, emotividad).

La reducción del sentimiento moral de empatía es una consecuencia de la identificación de la masculinidad con la razón instrumental ${ }^{82}$. Victor Seidler ha explicado que, mediante nuestra identificación racional, los hombres hemos aprendido a hablar con la voz de la Razón ${ }^{83}$. El uso del lenguaje impersonal y el sentimiento de autoridad que el autocontrol proporciona confieren a los hombres múltiples estrategias de poder que hacen que presenten sus intereses como la solución justa y objetiva para todos. Fácilmente, podemos observar cómo los hombres nos sentimos en posesión de la verdad absoluta en nuestras discusiones: argumentamos nuestra posición y justificamos nuestras conductas sin reflexionar sobre los sentimientos y las emociones de las personas implicadas (incluidas las nuestras) que subyacen al conflicto. Inducidos por el modelo hegemónico de masculinidad y por la valoración social que el androcentrismo comporta, los hombres aprendemos a vivir negando nuestras necesidades porque éstas son experimentadas como un signo de debilidad. Pero, "si nunca he aprendido cómo respetar mis propias emociones y sentimientos, y los experimento como signos de debilidad, entonces me va a ser difícil respetar las emociones y los sentimientos de otros" ${ }^{\prime 24}$. En la medida en que aprendemos a negar nuestras emociones y nuestras necesidades, nos volvemos más insensibles frente a las de los demás. La infravaloración constante

80. Amorós, C., La gran diferencia... p. 99.

81. Marques, J.V. y Osborne, R., Sexualidad...

82. Sambade, I., "Sobre las contradicciones...

83. Seidler, V., La sinrazón masculina...

84. Seidler, V., La sinrazón masculina... p. 203. 
que la cultura patriarcal realiza de las mujeres, su asociación con la debilidad y el miedo que genera para los hombres el poder verse identificados con las mismas son el caldo de cultivo de la misoginia y la violencia de género. Así, el endurecimiento de la empatía se convierte en una estrategia no sólo de control, sino también de sometimiento cuando la insensibilidad se produce frente al dolor de una mujer que espera la reciprocidad y el cuidado de su pareja. El menosprecio, el descrédito, la racionalización de la violencia, la culpabilización de la víctima, etc., son todas ellas estrategias de dominación desarrolladas por los maltratadores de mujeres que se originan en la ausencia absoluta de empatía.

La violencia de género es una lacra social que sigue aumentando en la mayor parte de las sociedades humanas, incluido en aquellas que existe una legislación vigente que la penaliza ${ }^{85}$. España es un ejemplo a este respecto ${ }^{86}$, al igual que el resto de países occidentales. La vinculación entre los modelos de representación audiovisuales de género y estos hechos ya ha sido mencionada, pero nos parece especialmente significativo el incremento exponencial de la violencia de género ejercida por hombres menores de edad ${ }^{87}$. Es más que probable que estos hechos estén vinculados con la representación de jóvenes héroes románticos con actitudes paternalistas, misóginas y antisociales en películas que han sido rotundos éxitos de taquilla (Crepúsculo, 50 sombras de Grey, A tres metros sobre el cielo). En estos relatos, las conductas de los héroes románticos son justificadas bajo la premisa de que lo que hacen, lo hacen por amor. Asimismo, su posición como protagonistas les dota de la deseabilidad inherente al sujeto de la esfera social pública, más incluso cuando son presentados como hombres con poder, incluido el poder de seducir y conquistar a los objetos de su deseo. Ahora bien, el seductor ya no es presentado como un personaje que engaña a las mujeres. Las mujeres representadas en estos relatos eligen libremente su destino. Como señala Walter, el discurso patriarcal contemporáneo ha incorporado la premisa de la libertad femenina como un sistema retórico de exculpación de los agresores ${ }^{88}$. Asistimos, de este modo, a una revitalización

85. ONU mujeres, Hechos y cifras: acabar con la violencia contra mujeres y niñas. Consulta 23 de octubre de 2018 (http://www.unwomen.org/es/what-we-do/ending-violence-againstwomen/facts-and-figures).

86. Instituto de la Mujer. Mujeres en Cifras - Violencia - Víctimas Mortales por Violencia de Género. Consulta 23 de octubre de 2018 (http://www.inmujer.gob.es/MujerCifras/ Violencia/VictimasMortalesVG.htm)

87. En España, el número de menores denunciados ha aumentado un 5,9 en 2016. Véase Moraleda, A., Aumentan las víctimas registradas de violencia machista por segundo año. El País, 31 de mayo de 2017. Consulta 23 de octubre de 2018 (http://politica.elpais.com/politica/2017/05/31/ actualidad/1496216239_724424.html). Asimismo, el alto número de víctimas de violencia de género menores de edad nos ofrece una muestra de la gravedad de este problema entre la juventud. Véase Instituto de la Mujer. Mujeres en Cifras...

88. Walter, N., Muñecas vivientes... 
del patriarcado basada fundamentalmente en el poder de definición social, un poder que se antoja más poderoso bajo el espejismo de la igualdad.

Resulta evidente que la represión de la emotividad dispuesta por la socialización en la masculinidad hegemónica patriarcal tiene también consecuencias sobre los propios hombres. Como explicó Celia Amorós, entre los pactos sociales que los hombres articulamos en torno a nuestra masculinidad están los pactos de fraternidad-terror:

Eres mi par porque por tu palabra me has dado poder sobre ti en la medida en la que yo te lo he dado sobre mí por la mía y un tercer cofrade ha sellado nuestro pacto garantizándonos a cada cual nuestra palabra contra el otro y contra sí mismo -por ello el anverso de la fraternidad es el Terror- so pena de la expulsión del grupo, o de liquidación física ${ }^{89}$.

Efectivamente, la presión social a la que están sometidos los hombres para confirmar su masculinidad puede resultar especialmente frustrante. Véase como ejemplo el caso de aquellos hombres homosexuales que acaban interiorizando la homofobia social en una especie de odio contra sí mismos ${ }^{90}$. Pero no se puede considerar que los hombres (como colectivo) sean víctimas sociales del sistema patriarcal ${ }^{91}$. La contrapartida de la instrumentalización de la propia persona es el disfrute de los dividendos patriarcales (doble moral, mayor libertad, incluida la sexual, mayor valoración social, mayores ingresos en posiciones análogas a las de las mujeres... $)^{92}$. Además, el disciplinamiento emocional provee a los hombres de estrategias para disociarse de las experiencias traumáticas: marcharse de casa después de una discusión, recluirse en el trabajo para olvidar los problemas personales, etc. Como explica Seidler, parece que a través del distanciamiento, los hombres aprenden a fragmentar su experiencia en una serie de sucesos sin relación o de circunstancias aisladas ${ }^{93}$. Este mecanismo psicológico de autoprotección se ve alentado por la vivencia de los dividendos patriarcales como la doble moral sexual.

Obviamente, ni los dividendos patriarcales ni las estrategias de distanciamiento y disociación resuelven las frustraciones que el modelo hegemónico de masculinidad, el modelo patriarcal en sus diferentes transfiguraciones, genera en la subjetividad de los hombres. Además, los dividendos patriarcales son mecanismos de reproducción de la desigualdad de género, de la injusta discriminación social de las mujeres y de su dominación y muerte a manos de

89. Amorós, C., La gran diferencia... p. 96.

90. Thompson, C. (2000). "Debemos rechazar la masculinidad tradicional", Thompson, K., Ser Hombre. Barcelona 2000, pp. 28-38.

91. Lo que no implica que no lo puedan ser a nivel individual, como en el caso de una agresión homófoba.

92. Connell, R.W., Masculinities...

93. Seidler, V., La sinrazón masculina... 
tantos hombres. Por este motivo, se ha defendido que el cambio hacia nuevas e igualitarias masculinidades debe de fundamentarse desde un eje triple que aúne la ética de la justicia, la ética del desarrollo humano y la ética del cuida$\mathrm{do}^{94}$. Es fundamental para este cambio que los hombres sean capaces de reconocer su propia vulnerabilidad. Sólo así, podrán desarrollar los sentimientos de empatía y solidaridad que requiere una ética del cuidado. Los modelos de representación de las masculinidades son fuertes obstáculos de este proceso de autocrítica: prácticamente no existen modelos en los que los hombres puedan reconocer su vulnerabilidad, y cuando existen, se ven alejados del paradigma androcéntrico de deseabilidad social.

\section{Conclusiones}

En las sociedades capitalistas de la información, el imaginario representado por los media instituye implícitamente la normalidad social ${ }^{95}$. Este imaginario es un continuo ilimitado de representaciones sobre lo real que se presentan a través de un discurso fragmentado, esquemático y estereotipado. De este modo, en el imaginario social confluyen las ideologías de los sistemas políticos, económicos y culturales que conforman nuestra idea de nosotros mismos como sociedad: nuestra conciencia social. Estas ideologías pueden ser contradictorias entre sí en la medida en que vivimos en sistemas políticos plurales y sociedades interculturales y estratificadas en función de clase, género, etnia y opción sexual. La fragmentación del discurso de los media permite una integración no conflictiva de representaciones contradictorias en un imaginario continuo y aparentemente coherente. Ahora bien, el imaginario social construido por los media funciona con la dinámica del capitalismo informacional. En el flujo del mercado, las personas ven representada su libertad a través de la capacidad de consumo ${ }^{96}$. Esto genera una especie de aristocracia natural sustentada por la ideología meritocrática, según la cual existen iguales condiciones para todas las personas, por lo que cada una ocupa en la sociedad el puesto que se merece $\mathrm{e}^{97}$. De este modo, si la precariedad laboral y económica atenta contra una vida íntegra en la realidad social, en el imaginario virtual, aquello que no es representado deja de existir ${ }^{98}$. No existe el fracaso, la pobreza, la injusticia o la discriminación. No existen porque no son representadas. No existen porque la idea de que cada cual ocupa el lugar que se ha ganado con sus propios méritos las hace invisibles. Por supuesto, en este imaginario,

94. Sambade, I., "Sobre las contradicciones...

95. Segarra, M., "Modelos de masculinidad y medios de comunicación", Segarra, M. y Carabí, À. (eds.), Nuevas Masculinidades. Barcelona 2000, pp. 151-176.

96. Sennett, R., La cultura del nuevo capitalismo. Anagrama 2006.

97. Sennett, R., La cultura del nuevo capitalismo...

98. López, M. y Gauli, J. C., "El cuerpo imaginado"... 
tampoco existen hombres sensibles hacia la discriminación de las mujeres y las propuestas feministas, como no existen hombres capaces de percibir su propia vulnerabilidad.

Dentro del fragmentado discurso audiovisual, se alimenta tanto la idea de que nuestras modernas sociedades se rigen por el paradigma democrático, como por la libertad (potencia) que genera el flujo del consumo. Estas ideas son parte de nuestra conciencia social. Se sustentan en el hecho de que tenemos una carta magna regida por los principios democráticos de lgualdad, Libertad y Solidaridad que, asimismo, se acoge al compromiso del respeto de los Derechos Humanos. Análogamente, tenemos un sistema jurídico formalmente igualitario, lo que obviamente no significa que exista igualdad de condiciones sociales y oportunidades. Esta conciencia social de igualdad se puede ver constantemente representada en los informativos de radiotelevisión, lo que, junto con la conciencia de los cambios sociales, genera el espejismo de la igualdad. Simultáneamente, nos encontramos con un sinfín de representaciones androcéntricas de masculinidad y femineidad. El hecho de que aparezcan representadas en los discursos publicitario y cinematográfico genera la idea de que esas representaciones no se corresponden con la realidad social, de que son mera ficción. Pero la realidad es que los modelos hegemónicos de representación de las masculinidades, modelos basados en el disciplinamiento físico y emocional y en las culturas del riesgo y la violencia, tienen su contrapartida en el destacado protagonismo de conductas antisociales por parte de los hombres. Asimismo, la violencia de género y la situación estructural de desigualdad son el correlato de una representación de la femineidad basada en la debilidad y la sexualización del cuerpo de las mujeres. Si estos hechos se perciben como hechos aislados o patologías individuales, más allá de la verdadera urdimbre patriarcal que reproduce una estructura de injusticia y discriminación social, es porque la representación fragmentada del imaginario audiovisual y mediático genera sensación de normalidad y éxito social a través de los modelos de belleza de género.

Análogamente, el sujeto de éxito social también tiene un contorno marcadamente masculino. Esta es la verdadera esencia de los modelos de belleza masculina. Metro, über y spornosexuales no son objetos de deseo, sino sujetos que desean ser deseados y que se ubican en la posición de objetos, sólo dentro de las posibilidades que les concede formar parte de una élite de la sociedad de consumo. Son deportistas profesionales, actores de cine y televisión, políticos; son hombres con poder de facto. Nada tiene que ver la contrapartida social del modelo hipersexualizado de femineidad, modelo que simboliza el supuesto poder femenino. Si bien existe una minoría de mujeres que han conseguido el éxito profesional, representando dicho modelo de femineidad, la verdadera correspondencia social del modelo hipersexualizado de femineidad no refiere a ninguna élite social, sino más bien a una masa ingente de mujeres victimizadas por el sistema prostitucional. Al igual que los hombres que puedan representar 
modelos alternativos de masculinidad, estas mujeres tampoco son prácticamente representadas.

En realidad, la representación de las mujeres es más bien escasa e irreal en el imaginario audiovisual. Más allá de su estatus vicario o de su objetivización sexual, las mujeres tienen una representación prácticamente anecdótica, más incluso cuando ocupan posiciones de autoridad en la clase social media (autoridad que detentan respecto a muchos hombres). Los sujetos del relato socialmente compartido son los hombres, lo que les confiere deseabilidad social en cada una de las múltiples, fragmentarias e incluso contradictorias representaciones de masculinidad.

Lejos de visibilizar esta estructura de desigualdad, los modelos de masculinidad y femineidad aparecen envueltos por el halo de la deseabilidad social y en aparente igualdad de condiciones. Los cánones de belleza de género los enraízan en un sistema de mercado en el que la imagen personal es objeto de consumo. Nos encontramos así con que la alianza entre el patriarcado y el capitalismo informacional es la estructura de la que emergen los modernos patriarcados de consentimiento. El patriarcado ha vuelto a reestructurarse conforme a las dinámicas sociales y económicas vigentes. Su metaestabilidad se hace manifiesta en la vigencia de los hombres como sujetos del relato socialmente compartido.

La reestructuración del patriarcado supone la reproducción de modelos de masculinidad que no sólo limitan las posibilidades de desarrollo humano de los hombres, sino que expone a las mujeres a una posición de desventaja y subordinación, cuando no de violencia y dominación explícita. Es necesario construir modelos de masculinidad basados en la vulnerabilidad y la mutua dependencia de los seres humanos, modelos que dispongan la solidaridad como la principal estrategia para el desarrollo de una sociedad justa y libre; una sociedad realmente democrática.

\section{Bibliografía}

Aguilar, P., "El cine, una representación patriarcal del mundo", Plaza, J. y Delgado, C. (eds.), Género y comunicación. Madrid, 2007, pp. 129-148.

Amorós, C., Hacia una crítica de la razón patriarcal. Barcelona, 1985.

Amorós, C., La gran diferencia y sus pequeñas consecuencias... para las luchas de las mujeres. Madrid, 2005.

Arranz, F., Cine y género en España. Madrid, 2010.

Badinter, E., XY. La identidad masculina. Trad. Monserrat Casals. Madrid, 1993. Bly, R., Iron John. New York, 1990.

Bourdieu, P., La dominación masculina. Trad. Joaquín Jordá. Barcelona, 2005. Clare, A., La masculinidad en crisis. Trad. Irene Cifuentes. Madrid, 2002. 
Connell, R.W., Masculinities. Sydney, AU, 1995.

Courneau, G., Père manquant, fils manqué. Québec, 1989.

Darbra Marges, S. y Martí-Carbonel, S., "Psicobiología de la conducta antisocial", Fisas, V., El sexo de la violencia. Barcelona, 1998, pp. 43-60.

David, D.S. y Brannon, R., The forty-nine percent majority: the male sex role. Massachusetts, 1976.

Davis, F., Moving the Mountain: The Women's Movement in America since 1960. Champaign, IL, 1999.

De Miguel, A. Neoliberalismo sexual. El mito de la libre elección. Madrid, 2015.

Elías, N. y Dunning, E., Deporte y ocio en el proceso de la civilización. Madrid, 1992.

Femenías, M.L. "Violencia de sexo-género. El espesor de la trama", Laurenzo, P., Maqueda, M.L. y Rubio, A. (eds.), Género, violencia y derecho. Valencia, 2008, pp. 61-88, p. 74.

Gil, E., El nuevo sexo débil. Madrid, 1997.

Gilmore, D., Hacerse hombre: concepciones culturales de la masculinidad. Barcelona, 1994.

González, J.M., “Uso y abuso de esteroides anabolizantes”. Osasunaz, 8, 2008, pp. 185-197.

Herrera, C., La construcción socio-cultural del amor romántico. Madrid, 2011.

Khun, C., Swartzwelder, S. y Wilson, W., Anabolizantes, estimulantes y calmantes en la práctica deportiva. Barcelona, 2003.

Kleinberg, S., "The new masculinity of gay men and beyond: Where have all the sissies gone?", Kimmel, M. y Messner, M. A. (eds.), Men's lives. New York, 1978/1989, pp. 101-114, p. 109.

López, M. y Gauli, J. C., "El cuerpo imaginado". Revista Complutense de Educación, 11 (2), 2000, pp. 43-58.

López, P., $2^{\circ}$ informe de la investigación: representación de género en los informativos de radio y televisión. Madrid, 2006.

López, P., Bengoechea, M., Díaz-Aguado, M. J. y Falcón, L., "Representación, estereotipos y roles de género en la programación infantil 1", Infancia, televisión y género. Guía para la elaboración de contenidos no sexistas en programas infantiles de televisión. Madrid, 2005.

Marqués, J.V. y Osborne, R., Sexualidad y sexismo. Madrid, 1991.

Middleman, A.B. et al., "High-risk behaviors among high school students in Massachusetts who use anabolic steroids". Pediatrics, 96, 1995, pp. 268-272.

Molina, C., Dialéctica feminista de la ilustración. Barcelona, 1994.

Moraleda, A., "Aumentan las víctimas registradas de violencia machista por segundo año". El País, 31 de mayo de 2017. Disponible en: http://politica.el- 
pais.com/politica/2017/05/31/actualidad/1496216239_724424.html (Consulta: 23 de octubre de 2018).

Parkinson, A.B. y Evans, N.A., "Anabolic androgenic steroids: a survey of 500 users". Medecine \& Science in Sports \& Exercise, 38 (4), 2006, pp. 644-651.

Plumwood, V., Feminism and the Mastery of Nature. London y New York, 1993.

Puleo, A. H., "Patriarcado", Amorós, C. (dir.), 10 palabras clave sobre Mujer. Estella, 1995, pp. 21-54.

Ruthven, A., "La violencia sexuada en los cómics. ¿Quién salvará el mundo?", Martín Lucas, B. (ed.). Violencias (in) visibles. Barcelona, 2010, pp. 161-176.

Sáez, J., "Excesos de la masculinidad: la cultura leather y la cultura de los osos", Grupo de trabajo Queer (ed.), El eje del mal es heterosexual. Figuraciones, movimientos y prácticas feministas queer. Madrid, 2005, pp. 137-148, p. 146.

Salazar, O., La igualdad en rodaje: masculinidades, género y cine. Valencia, 2015.

Saltzman, M., Matathia, I. y O’Reily, A., The future of man: the rise of übersexual and what he means for marketing today. New York, 2005.

Sambade, I., "La construcción social del cuerpo masculino: género, salud y conducta antisocial". Género y salud en cifras, 14 (3), 2017, pp. 6-18.

Sambade, I., "La instrumentalización de la sexualidad. Masculinidad patriarcal, pornografía y prostitución", De Miguel, A. y Nuño, L. (eds.), Elementos para una teoría crítica del sistema prostitucional. Granada, 2017, pp. 169-180.

Sambade, I. y Torres, L., "Cuerpo e identidad de género en la sociedad de la información", Puleo, A. (ed.), Ecología y género en diálogo interdisciplinar. Madrid, 2014, pp. 65-80.

Sambade, I., "Sobre las contradicciones de la razón moderna y la constitución de la subjetividad masculina". Prisma Social. Revista de Ciencias Sociales, 13, 2014, pp. 787-851.

Sambade, I., "La pragmática masculina del control: del gobierno de sí mismo hacia la violencia contra las mujeres". Nomadías, 11, 2010, pp. 42-68.

Segal, L., "Los hombres tras el feminismo ¿Qué queda por decir?", Carabí, A. y Armengol, J. M. (eds.), La masculinidad a debate. Barcelona, 2008, pp. 155-177.

Segarra, M., "Modelos de masculinidad y medios de comunicación", Segarra, M. y Carabí, À. (eds.), Nuevas Masculinidades. Barcelona, 2000, pp. 151-176.

Seidler, V., La sinrazón masculina. México, 2000.

Sennett, R., La cultura del nuevo capitalismo. Barcelona, 2006.

Simpson, M., "Meet the metrosexual". Salon.com (blog), 22 de julio de 2002. Disponible en: http://www.salon.com/2002/07/22/metrosexual/ (Consulta: 22 de junio de 2017). 
Simpson, M., "Objectify yourself. Why straight young men crave gay adulation". OUT (blog), 6 de enero de 2015. Disponible en: http://www.out.com/ entertainment/2015/01/06/objectify-yourself-why-straight-young-men-cravegay-adulation (Consulta: 18 de junio de 2017).

Simpson, M., "Sporno". Marksimpson.com (blog), 17 de abril de 2010, Disponible en: http://www.marksimpson.com/blog/2010/04/17/sporno/ (Consulta: 21 de junio de 2017).

Smith, S., Choueiti, M. y Pieper, K., Gender Inequality in Popular Films: Examining On Screen Portrayals and Behind-the-Scenes Employment Patterns in Motion Pictures Released between 2007-2013, USC Annenberg and Media, Diversity, \& Social Change Initiative supporters, Los Angeles, 2014.

Thompson, C., "Debemos rechazar la masculinidad tradicional", Thompson, K., Ser Hombre. Barcelona, 2000, pp. 28-38.

Valcárcel, A., Feminismo en el mundo global. Madrid, 2008.

Walter, N., Muñecas vivientes. El regreso del sexismo. Trad. María Álvarez Rilla. Madrid, 2010.

Yesalis, C.E., Courson, S.P. y Wright, J., "History of anabolic steroid use in sport and exercise", Yesalis, C.E. (ed.), Anabolic steroids in sport and exercise. $2^{\text {a }}$ ed. Champaign, 2000, pp. 51-71.

Yrache, L., "Imagen de la mujer y el hombre en publicidad", Plaza, J. y Delgado, C. (eds.), Género y comunicación. Madrid, 2007, pp. 101-128. 